\title{
Vibration technique for monitoring termite induced degradation in trees
}

\author{
Prakash Jadhav \\ Department of Mechanical Engineering, SRM University, Andhra Pradesh, India \\ E-mail: prakash.j@srmap.edu.in \\ Received 1 October 2020; received in revised form 8 October 2020; accepted 14 October 2020 \\ DOI https://doi.org/10.21595/vp.2020.21717
}

Check for updates

Copyright $(C) 2020$ Prakash Jadhav. This is an open access article distributed under the Creative Commons Attribution License, which permits unrestricted use, distribution, and reproduction in any medium, provided the original work is properly cited.

\begin{abstract}
Termites infestation is a big problem for trees. It is also very difficult to find the trees with termite damage. It is essential to find the trees with initial level of termite damage so that the trees can be treated with suitable available treatments. It is proposed here a new technique using vibration analysis which can detect the termite damage inside the tree trunks by just performing very simple vibration experiment. This method is cheap, efficient and can potentially save large number of trees from dying due to termite infestation. By performing laboratory level experiments, this research proves the feasibility of this simple technique of damage detection in trees.
\end{abstract}

Keywords: structural damage detection, tree, termite.

\section{Introduction}

Termite infestation in forests was recently found to be increasing at a startling rate. It is estimated that termites cause damage to trees, plants, homes worth US \$50 billion worldwide per year. Also, approximately $20 \%$ trees in the forest are infected with termites more or less. There are at least 200 species of termites spread over the world. There is not much work published on tree termite damage assessment techniques. This paper describes one of the technique here which if used, can save thousands of trees worldwide. Early termite detection in trees is essential to identify which trees require treatment in order to prevent eventual collapse. The process of treating every tree is very costly and inefficient; hence an approach for detecting the presence of termites in trees is important. Some researchers have tried to use non-destructive evaluation techniques like acoustic monitoring using sensors successfully to detect termites and the damage [1-4]. These researchers try to detect sounds created by termites to access the termite damage and also; drilling small holes in the trees and assessing the damage using acoustic sensors

Vibration techniques provide another approach for detecting termite-induced degradation in trees, over a period of time. Vibration techniques have been used for damage detection in many other structural applications [5-7]. Generally, vibrations techniques are used for damage detection in structures with less damping such as metals. However, the material under consideration in current research is wood which is highly damped. This research introduces a vibration approach that may be used for termite- induced degradation, and the feasibility of these methods through laboratory testing. The approach involves exciting a steel stake that is inserted into a tree stump and comparing the response obtained from the stake. The effect of moisture on the modal frequencies was also studied. It should be noted that the techniques presented here are used to detect termite activity over a period of time, compared to a baseline data.

\subsection{Embedded steel stake technique}

This idea is based on a fundamental vibration concept that the dynamic response of a structure is also dependent upon its boundary condition. Instead of acquiring and comparing the vibration response or signature of the whole tree, another approach would be to compare the response of a steel stake that is driven into a tree. The presence or progression of termite damage after certain duration is expected to weaken the region of the tree holding the stake. This change in 'boundary condition' of the stake in turn would cause a change in the stake's vibration response i.e. shift the 
modal frequencies, which could be used to identify the presence of damage. In real applications, the stake would be driven closer to the base of the tree where termite damage is often most extensive, which could lead to the tree falling.

This approach has several advantages. It is less dependent on external environmental factors like dropping of branches and leaves and growth of the tree root, since the response is dependent only on the section of the tree close to where the stake is driven. Increase in trunk diameter on the contrary, might affect the vibration response, however this only occurs after a substantial duration of time. Secondly, steel provides a cleaner and more accurate dynamic response compared to an actual tree, which is a highly damped and complex structure. The setback to this approach is that termite damage might not be present at the region near where the stake is located. Multiple stakes at different locations might be used to compensate this setback.

Fig. 3 shows a sketch of the steel stake and trunk. The stake consists of two sections; the sharp spike end, which is driven into the tree and the square sectioned shaft to facilitate the mounting of accelerometer and hammer excitation. Preliminary computation of the expected natural frequencies was made before designing the stake to obtain the optimum length and cross section area, using the basics. It is desirable to have as low a frequency as possible without affecting the integrity of the stake, since higher frequencies measurements are less reliable due to the noise and other factors. Having too small a cross section and too long a stake might cause buckling or bending problem when driving it into the tree trunk. The first two flexural modes were approximately $385 \mathrm{~Hz}$ and $2415 \mathrm{~Hz}$ respectively, while the first extensional mode for the 8-inch stake is calculated to be $6363 \mathrm{~Hz}$. The steel stake was driven approximately $50 \mathrm{~mm}$ from the top surface of the tree stump sample. It is not feasible to locate the stake any lower since it is not possible to create damage at such depth using conventional hand-held drill. The artificially induced damage must be close to where the spike end is located for validating this technique.

Fig. 1 shows the experimental setup for this approach. The force transducer is a PCB Piezotronic Impulse Force Hammer with a force range between 0 to $50 \mathrm{~kg}$. It was initially planned that a tri-axial accelerometer be used for this experiment, but unfortunately, it is presently not available. Instead, a PCB Piezotronic Model uniaxial accelerometer (frequency range between $5 \mathrm{~Hz}$ to $8 \mathrm{kHz}$ and sensitivity of $10.92 \mathrm{mV} / \mathrm{g}$ ) was used. The hammer is connected to Channel 1 , while the accelerometer is connected to Channel 2 of Photon, a 4-channel data acquisition system. The Photon system is interfaced to a laptop computer via a USB cable. Both the transducers and Photon system are powered by the laptop, thus increasing its mobility and allowing actual testing to be performed on-site.

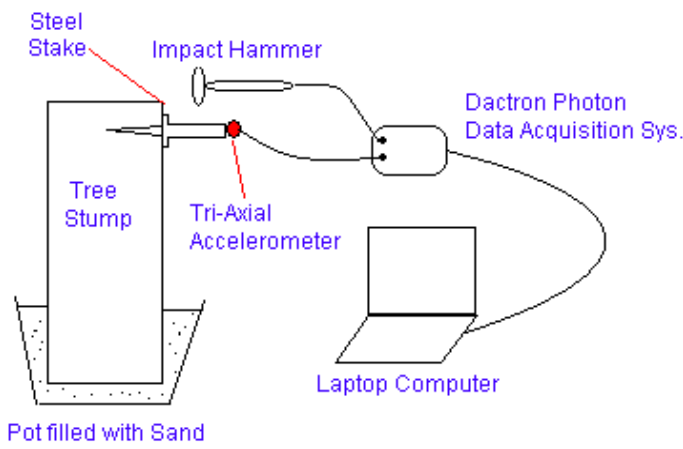

Fig. 1. Experimental setup for obtaining vibration response of steel stake

For the uni-axial accelerometer, its location has to be moved depending upon the measured direction. The impact hammer was used to excite the stake at multiple directions, as shown in Figs. 2 and 3. Impacting the stake in the $x$ - and $y$-direction will excite the flexural modes of vibration in those planes, while hitting at the $z$ - direction will excite the extensional modes of vibration. A total of 5 averages were obtained for each component. 
The response is picked up and generated in the form of a frequency response function (FRF). The quality of each measurement i.e. whether it is acceptable, can be determined by checking the coherence data of each response. Coherence is the measure of how much output response generated is due to the input excitation. An acceptable response would indicate a value close to ' 1 ' throughout most of the measuring frequencies.

Each peak in the FRF corresponds to one mode of vibration with unique modal frequency. As mentioned, these modal frequencies will be used to detect termite degradation by monitoring any shift in the frequencies, assuming that the frequencies are affected only by termite damage and moisture. Hence, it is important to keep all boundary condition parameters constant. A set of modal frequencies are obtained for the baseline (undamaged), wet and damaged condition respectively.

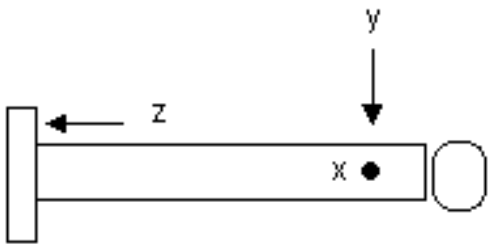

Fig. 2. Impact direction

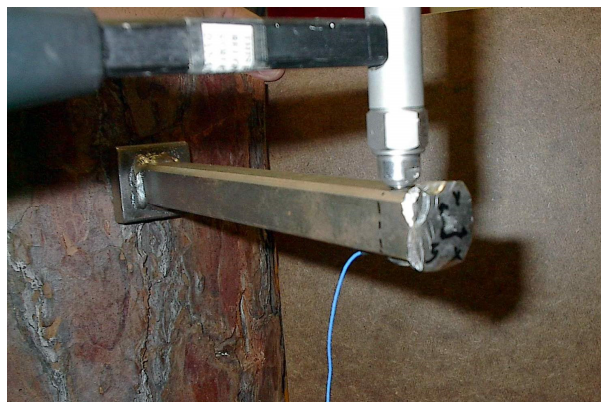

Fig. 3. Data acquisition in $y$-direction

\section{Experimental set up and procedure}

To facilitate preliminary laboratory testing, a section of a pine tree trunk was used. The tree trunk, measuring $325 \mathrm{~mm}$ diameter and 1,2 $\mathrm{m}$ height, was planted upright in a plastic pot, filled with sand, as shown in Fig. 1. Preliminary responses of the undamaged trunk for both techniques were first obtained.

To study the effects of moisture, the tree trunk was exposed to water shower for a certain time period, before repeating the same impact testing procedure for getting another set of response. Five small cubic blocks were cut off from the tree stump sample prior to obtaining the baseline (undamaged) response. These pieces were used for estimating the amount of moisture absorbed by the wood, during exposure to water shower for similar duration as the tree trunk. The volume and weight of each piece was measured and recorded before and after subjecting to water shower. The percentage change in density was then computed. The blocks are approximately $50 \times 50 \times 50 \mathrm{~mm}$ in dimensions. This gives the amount of absorbed water by the wood. The value obtained does not exactly represent the amount of water absorbed by the trunk since water is not distributed uniformly throughout the trunk. It is expected that the moisture absorption of the area close to the exposed surface will be closer to that of the wooden blocks. This is a reasonable approximation for this approach as the stake is located close to the top surface. The trunk was subject to shower water (approximately 0.29 -liters/sec) for duration of 24 hours. The percentage moisture absorbed by the wooden blocks is tabulated in Table 2 .

A few vibration response measurements were gathered after cumulative levels of artificial damage were created from the top of the tree trunk. Damage was induced only after the tree stump dried. The weight of the wooden blocks was used to ensure that the tree trunk is dry. Artificial damage was created using a hand-held drill, to simulate termite damage, as it would be too time-consuming to allow the termites to physically damage the tree trunk. Damage was created from the top surface of the trunk. A total of four separate levels of damage were created around the region where the spiked end is located within the trunk. 1st level damage was simulated through uniform damage around the region (Fig. 4). Concentrated damage at the center of the trunk was created to simulate 2 nd level damage (Fig. 5), while the 3rd level damage includes 
concentrated damage at the outer region (Fig. 6). For simulating the 4th level damage, a larger drill bit was used to simulate a highly concentrated final damage.

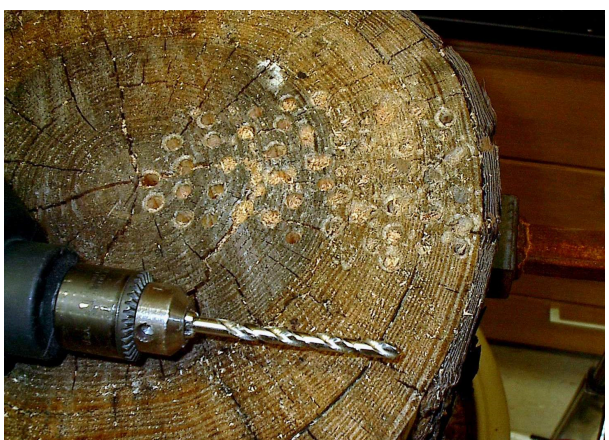

Fig. 4. First level damage

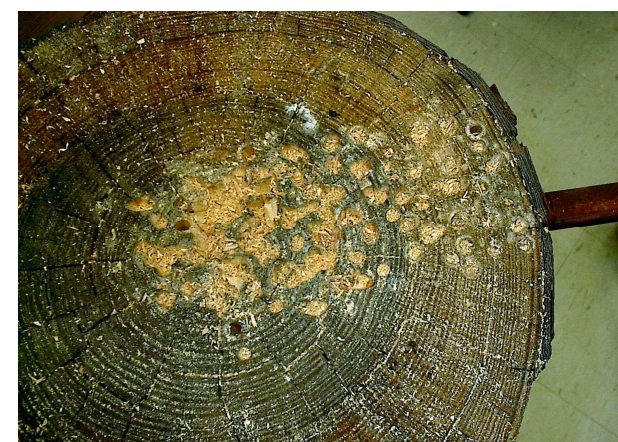

Fig. 5. 2nd level damage

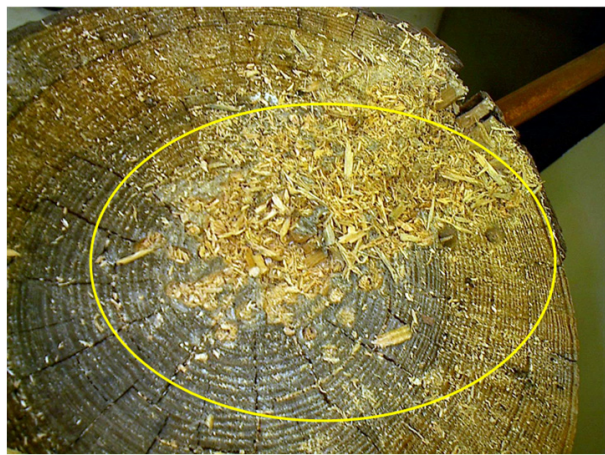

Fig. 6. Final level damage

\section{Results and discussions}

A total of 4 flexural modes were measured for the $x$ - and $y$-direction. Only one mode was captured in the extensional $z$-direction. The frequencies were found to be much lower than the calculated theoretical frequencies. Table 1 lists the change in weight and percentage moisture absorption of the wood. Tables 2 and 3 list the measured modal frequencies for second steel stake approach for $x$ - and $y$-direction respectively. No distinct peaks appeared in the $z$-direction after damage induction and were therefore dropped. The values in the first sub-column are the measured modal frequencies while the values in the second sub-column are the percentage reduction in frequencies from the baseline frequencies.

The first two modes were primarily used for monitoring termite infestation. The third and fourth modes appear to be damped for most cases. A slight discrepancy in the frequencies between the flexural $x$ - and $y$-directions was observed for all the modes. Ideally, it should be identical if the stake is symmetrical. Also, the pot is not fixed to the ground. Although the mass of the whole tree-pot configuration is massive enough that rigid motion is not visually noticeable, the accelerometer is sensitive enough to pick up any frequency offsets.

From Tables 2 and 3, it appears that moisture has only small effect on the frequency. The third and fourth modes appeared to be highly damped, as a result of the wet condition. The addition of moisture increases the frequencies a little (app. 1 to $3 \%$ ). Comparison between the undamaged and first level damage shows a drop in the frequencies (between 3-11\%). Concentrated damage at the center region (2nd level damage) increases the frequencies (when compared with the 1st level damage) by about 1 to $2 \%$. Concentrated damage at the outer region (3rd level damage) shows a drop in frequencies from 2 nd level damage. When the frequencies of the 1 st and 3 rd level 
of damage are compared with the baseline frequencies, the effect of 3rd level was observed to be greater. The 4th level damage shows the highest drop in frequencies (app. 15-20\%). Inducing severe damage away from the steel stake does not cause any change in modal frequencies.

It is expected that the frequencies of the steel stake decrease, as more damage is created and the region holding the steel stake is weakened. This is observed after the 1st level damage is created. A slight increase in the frequencies is noted after 2 nd level damage is created, while the addition of 3 rd level damage causes a decrease in the frequencies. This shows that damage location does play a role in the amount of decrease in modal frequencies. Concentrated damage near region supporting the greater part of the spike will have greater effect on the modal frequencies. In this case, the 3rd level damage (at the outer region) has greater effect i.e. reduction on the modal frequencies compared to the 2 nd level damage (at the center) since a large section of the spike is located where the 3 rd level damage is present.

Table 1. Percentage moisture absorption of individual wooden blocks

\begin{tabular}{|c|c|c|c|c|c|}
\hline & $\# 1$ & $\# 2$ & $\# 3$ & $\# 4$ & $\# 5$ \\
\hline Initial dry weight (g) & 69.05 & 79.73 & 67.47 & 76.60 & 82.32 \\
\hline Wet weight (g) & 91.10 & 100.32 & 135.95 & 138.07 & 109.15 \\
\hline \% moisture absorption & 31.93 & 25.82 & 101.50 & 80.25 & 32.59 \\
\hline Weight after drying (g) & 68.96 & 79.61 & 63.84 & 73.47 & 81.59 \\
\hline
\end{tabular}

Table 2. Experimental modal frequencies (Hz) for $x$-direction

\begin{tabular}{|c|c|c|c|c|c|c|c|c|c|c|c|}
\hline $\begin{array}{c}\text { Mode } \\
\#\end{array}$ & $\begin{array}{c}\text { Baseline } \\
\text { (Undamaged) }\end{array}$ & \multicolumn{2}{|c|}{ Wet } & \multicolumn{2}{c|}{$\begin{array}{c}\text { st level } \\
\text { damage }\end{array}$} & \multicolumn{2}{c|}{$\begin{array}{c}\text { 2nd level } \\
\text { damage }\end{array}$} & \multicolumn{2}{c|}{$\begin{array}{c}\text { 3rd level } \\
\text { damage }\end{array}$} & \multicolumn{2}{c|}{$\begin{array}{c}\text { Final } \\
\text { damage }\end{array}$} \\
\hline & $\mathrm{Hz}$ & $\mathrm{Hz}$ & $\%$ & $\mathrm{~Hz}$ & $\%$ & $\mathrm{~Hz}$ & $\%$ & $\mathrm{~Hz}$ & $\%$ & $\mathrm{~Hz}$ & $\%$ \\
\hline 1 & 105 & 104.4 & 0.57 & 92.5 & 11.9 & 95 & 9.5 & 93.75 & 10.7 & 86.6 & 17.5 \\
\hline 2 & 940 & 950 & -1.06 & 918.5 & 2.3 & 927 & 1.4 & 835 & 11.2 & 735 & 21.8 \\
\hline 3 & 2420 & - & - & 2345 & 3.1 & 2400 & 0.8 & 2292 & 5.3 & 2002 & 17.3 \\
\hline 4 & 5290 & - & - & 5018 & 5.1 & 5020 & 5.1 & 5015 & 5.2 & 4968 & 6.1 \\
\hline
\end{tabular}

Table 3. Experimental modal frequencies (Hz) for $y$-direction

\begin{tabular}{|c|c|c|c|c|c|c|c|c|c|c|c|}
\hline $\begin{array}{c}\text { Mode } \\
\#\end{array}$ & $\begin{array}{c}\text { Baseline } \\
\text { (Undamaged) }\end{array}$ & \multicolumn{2}{|c|}{ Wet } & \multicolumn{2}{c|}{$\begin{array}{c}\text { 1st level } \\
\text { damage }\end{array}$} & \multicolumn{2}{c|}{$\begin{array}{c}\text { 2ndevel } \\
\text { damage }\end{array}$} & \multicolumn{2}{c|}{$\begin{array}{c}\text { 3rd level } \\
\text { damage }\end{array}$} & \multicolumn{2}{c|}{$\begin{array}{c}\text { Final } \\
\text { damage }\end{array}$} \\
\hline & $\mathrm{Hz}$ & $\mathrm{Hz}$ & $\%$ & $\mathrm{~Hz}$ & $\%$ & $\mathrm{~Hz}$ & $\%$ & $\mathrm{~Hz}$ & $\%$ & $\mathrm{~Hz}$ & $\%$ \\
\hline 1 & 110 & 113.7 & -3.36 & 106.9 & 2.8 & 107.5 & 2.3 & 103.7 & 5.7 & 94.5 & 14.1 \\
\hline 2 & 1150 & 1162 & -1.04 & 1121 & 2.5 & 1129 & 1.8 & 1117 & 2.9 & 1005 & 12.6 \\
\hline 3 & 2600 & - & - & - & - & - & & 2546 & 2.1 & 2325 & 10.6 \\
\hline 4 & 5480 & - & - & 5000 & 8.8 & 5020 & 8.4 & 5030 & 8.2 & 4955 & 9.6 \\
\hline
\end{tabular}

A larger and longer drill bit was used to create substantial damage inside the trunk. A noticeable drop of 15 to $20 \%$ was recorded. The amount of frequency reduction is dependent upon two parameters i.e. magnitude or severity of damage and location where the damage propagates.

Minimal effect of moisture on the modal frequencies indicates that the modal frequency is more sensitive to damage than moisture, thus making this approach feasible for damage detection. However, as the results show, this approach works better for detecting larger damage, and might not be sensitive enough to detect small termite damage at an early stage.

The addition of 5th and 6th damage lowers the frequencies of all the modes further. The drop in frequencies however is not as great as the drop caused by 4th level damage, which is located at a region around the stake. This shows that this approach is best used to detect termite damage propagation that is located at regions close to the location of the steel stake. However, it does show some sensitivity to detecting damage at regions away from the stake, provided the damage is severe. For this approach to work effectively, multiple stakes can be inserted at different locations around the base of the tree trunk to increase the probability of detecting progressive damage 
caused by Formosan subterranean termites.

\section{Conclusions}

A vibration-based technique for detecting termite-induced degradation in trees was investigated. Two different approaches were used. The first approach utilizes a square sectioned steel stake with a sharp anvil that is driven into the tree. The stake is excited and its response compared. The second approach involved exciting the whole trunk itself and comparing its vibration response i.e. modal frequencies, from a tri-axial accelerometer attached directly onto the tree, before and after damaged. Furthermore, the effects of moisture on the modal frequencies were studied by subjecting the tree trunk to simulated rainfall for a short duration. A hand drill was used for creating artificial damage to the tree trunk. Six different levels of damage were created at different locations to monitor damage progression and the effect of damage location on the modal frequency shifts was studied.

The first approach was carried out using a uniaxial accelerometer. It was found that the modal frequencies drop as a result of induced damage. The amount of frequency reduction was dependent upon two parameter i.e. magnitude or severity of damage and location. The more severe the damage, the greater the shift in frequency. Propagation of damage near the region where the steel stake is located had a greater effect on the frequency. The second approach will be further investigated at later date as and when the tri-axial accelerometer is available. This simple technique if applied, can save thousands of trees in the forests worldwide from dying and also it can billions of dollars that are spent on pest control in the plantations.

\section{References}

[1] Wang X., Allison R. B. Decay detection in Red Oak Trees using a combination of visual inspection, acoustic testing and resistance microdrilling. Arboriculture and Urban Forestry, Vol. 34, 2008, p. 1-4.

[2] Wang X., Weindenbeck J., Liang S. Acoustic tomography for decay detection in black cherry trees. Wood and Fibre Science, Vol. 41, 2016, p. 127-137.

[3] Lin C. J., Huang Y. H., Hunag G. S., Wu M. L., Yang T. H. Detection of termite damage in hoop pine trees using non destructive evaluation techniques. Journal of Tropical Forest Science, Vol. 28, Issue 1, 2016, p. 79-87.

[4] Mankin R. W., Osbrink W. L., Oi F. M., Anderson J. B. Acoustics detection of termite infestation in urban trees. Journal of Economic Entomology, Vol. 95, Issue 5, 2002, p. 981-988.

[5] Lay Menn Khoo, Raju Mantena P., Prakash Jadhav Structural damage assessment using vibration modal analysis. Structural Health Monitoring, Vol. 3, Issue 2, 2004, p. 177-194.

[6] Prakash Jadhav, P Raju Mantena Analytical and experimental assessment of damage in wooden beams using vibration response measurements. ASME Southeastern Region XI Technical Journal, 2002.

[7] Prakash Jadhav Damage assessment in a wall structure using resonant frequencies and operating deflection shapes. International Journal of Mechanical Engineering and Technology, Vol. 8, Issue 3, 2017, p. 95-107. 